\title{
Sectoral Growth Effects of Energy Policies in an Increasing-Varieties Model of the Swiss Economy
}

\author{
Lucas Bretschger ${ }^{a}$ and Roger Ramer ${ }^{b}$
}

JEL-Classification: Q54, C63, O41, Q43.

Keywords: Energy and Growth, CGE model, sectoral growth rates, Swiss data.

\section{Introduction}

Climate change, the ongoing depletion of natural resource stocks and recent catastrophic accidents of energy suppliers have refueled the public debate about future energy supply and an appropriate energy mix. Policy makers often address these challenges with a view towards sustainable development. The term "sustainability" summarizes several targets, such as non-decreasing future living standards, protection of the natural environment, and the reduction of risks due to ecological and economic crises. On a sustainable path, the global energy system needs to be compatible with the natural environment.

The Swiss government addresses the challenges of future energy use with various policies and envisages different scenarios. The most ambitious target that has been intensively discussed is the vision of a cut of total energy use by two thirds in the long run. As current energy use per capita is about $6 \mathrm{~kW}$, the vision has been called "2000-Watt-society". The target should not be taken as a precise number, but rather contains the clear message that one of the main keys to solving the energy problem is a drastic increase in energy efficiency. The interesting aspect associated with efficiency targets is that they are closely linked to investments and innovation, which are generally believed to be important for economic growth.

a CER-ETH Center of Economic Research at ETH Zurich, ZUE F7, CH-8092 Zurich, Switzerland Tel.+41 4463221 92,Fax+41 4463213 62, email: lbretschger@ethz.ch.

b CER-ETH Center of Economic Research at ETH Zurich.

Acknowledgements: The authors thank Frank Vöhringer for his assistance in programming the simulation model, Florentine Schwark for her work on the underlying theoretical model, and Nicole Mathys, Matthias Gysler, Thomas Rutherford and Philippe Thalmann for their valuable comments. 
While energy efficiency policies may offer plenty of opportunities for certain industries, critics often argue that other sectors are negatively affected and will even suffer losses. Moreover, the overall impact is not clear when some sectors lose and others win. Hence, the consequences of policies aiming at an average energy use of 2000 Watt have to be carefully studied. We need to evaluate the consequences for overall growth as well as for sectoral growth in order to derive predictions about the triggered structural shifts in the economy, an aspect that has not been thoroughly investigated yet.

Given the importance of technological advances and research in this context, a model that studies a policy with such an ambitious goal should explicitly consider the role of innovation, its relationship with environmental regulation and its impact on economic development. In this paper, we present an approach where these links are explicitly captured. We first develop a framework that includes an endogenous growth mechanism driven by expanding varieties to investigate the effects of a decreasing energy input. We then apply a multisectoral computable general equilibrium (CGE) model that builds on the approach developed in the theoretical section to study the impacts of a policy that aims at the ultimate goal of a 2000-Watt-society in Switzerland. A key point of interest regards the structural effects that may be associated with such a policy.

In this paper, we focus on the relationship between energy use and growth. The theoretical model predicts that the effects of energy use on growth are not positive but ambiguous in general; under certain conditions, a decreasing energy input does not harm but may even spur economic development. If energy cannot easily be substituted by other production factors (which is the relevant case), decreasing energy inputs redirects inputs to capital accumulation and thereby leads to increased investments in productivity-enhancing capital. The simulations using data for the Swiss economy confirm this result in the sense that (i) the aggregate effects of an ambitious energy efficiency policy turn out only moderately negative, (ii) all sectors in the economy continue to grow at robust positive rates (although growth rates decrease in some sectors compared to business-as-usual), and (iii) some industries even experience substantially higher growth under regulation.

The theoretical approach of the model is related to Romer (1990) and Grossman and Helpman (1991). The incentives to invest in the expansion of varieties arise endogenously and provide the basic mechanism for productivity and consumption growth. The associated gains of specialization have been formally introduced to economic models by Spence (1976), Dixit and Stiglitz (1977), and ETHIER (1982). The interplay between environmental policy, innovation and economic (or sectoral) development has been studied by Xepapadeas and DE Zeeuw (1999), Smulders and de Nooij (2003), and Pittel and Bretschger 
(2010). We restrict our attention to the accurate inclusion of the expanding variety approach and abstract from other drivers of technological change. The model focuses on the macroeconomic impacts of energy policies using an aggregate representation of the energy sector. The main contribution of the paper is the combination of fully-specified endogenous growth theory with numerical CGE modeling in order to predict aggregate and sectoral growth rates in the future.

A more frequent representation of endogenous technical change in top-down CGE models is given by knowledge stocks that are typically accumulated with the help of R\&D investments. Knowledge stocks with a general total factor productivity effect are used e.g. in Goulder and Schneider (1999), Nordhaus (2002), Buonanno, Carraro and Galeotti (2003), Sue Wing (2003) or Отto, Löschel and Delink (2007). These studies acknowledge the need to include induced innovation but generally find that it is less powerful than input substitution, because the R\&D efforts as a share of GDP are small. The difference to our approach is the link between the different investment types. We stress that induced innovation has a strong and positive effect on all other forms of investment, in particular physical capital investment. The economy also benefits from investments in new infrastructure or from energy-saving renovations of buildings (and hence from improvements of the physical capital stock), which is a crucial aspect in any energy-policy context. More recently, several models use learning rates (an approach that is more frequently implemented in bottom-up or energy system models) in addition to the accumulation of knowledge capital. Examples are Edenhofer, Bauer and Kriegler (2005) and Bosetti, Carraro and Galeotti (2006). Contrary to these approaches, there are no exogenous factors or autonomous energy efficiency improvements in our model; growth is entirely driven by the increasing-variety mechanism and thus fully endogenous. A CGE model using gains from specialization is used in HEGGEDAL and JACOBSEN (2011), but there, only a small fraction of growth is assumed to be endogenous and the largest part of economic development is driven by exogenous technical progress. In BRETSCHGER, RAMER and SCHWARK (2011), a similar framework is used but applied for evaluating long-run carbon policies ${ }^{1}$. The present paper provides the explicit microfoundations for the expansion-in-varieties model in the context of energy and evaluates and discusses a completely different set of policies, inspired by the current energy policy debate.

1 To be more precise, we use a similar version of the simulation model to investigate the effects of a reduction target for carbon emissions of $80 \%$ until 2050 . We find slightly stronger effects on welfare and sectoral growth rates than in the present paper due to the higher stringency and the longer time frame of the policies. 
The remainder of the paper is organized as follows. Section 2 presents the theoretical approach. Section 3 explains the data set and the parametrization of the simulation model. Section 4 presents the results of the policy analysis and discusses the impacts of a policy aiming at a 2000-Watt-society. Section 5 checks for the robustness of the model results with a brief sensitivity analysis. Section 6 concludes.

\section{Increasing Varieties and Energy}

We conduct our numerical simulations with the CITE (Computable Induced Technology and Energy) model, which is a CGE model based on endogenous growth. The formal structure of the model is described in detail in BRETSCHGER, Ramer and Schwark (2011) and Bretschger, Ramer and Schwark (2010). The nested production functions are available in the Appendix (Figures 6 and 7). In this section, we aim at highlighting the underlying expanding variety mechanism and the interplay between energy use, capital accumulation and growth.

The dynamic impact of energy is based on an enriched theoretical approach with increasing goods varieties, including the following features.

Capital accumulation rate: In each sector, an intermediate composite $Q$ is assembled from (heterogenous) intermediate good varieties $x_{j}$ according to

$$
Q=\left[\int_{0}^{N} x_{j}^{\beta} d j\right]^{\frac{1}{\beta}}
$$

where $0<\beta<1$ and $N$ is the number of intermediate varieties. With symmetric intermediates $x_{j}=x$ it reads

$$
Q=N^{\frac{1-\beta}{\beta}} X
$$

with $X=n \cdot x$ for the aggregate output of the $x$-firms. $(1-\beta) / \beta$ reflects the gains from diversification. From (2) we see that the growth rate of the intermediate composite $(\dot{Q} / Q$ with $\dot{Q}=\partial Q / \partial t)$ depends on the growth rate of intermediates' production $(\dot{X} / X)$ and the capital accumulation rate $(\dot{N} / N=g)$, which we determine next. New intermediate varieties arise whenever a new (differentiated) capital good is available. If only knowledge capital is considered, this is usually called a "patent" or a "blueprint". As we also include the accumulation 
of physical capital, we call it more generally "new capital variety", where capital is composed of different capital types. The inclusion of physical capital in this context is straightforward. Improvements in physical and knowledge capital are closely related. Newly acquired knowledge resulting from efforts research and development is often embodied in physical capital, e.g. in more productive machines or in more efficient insulation. It is therefore not only knowledge capital itself that influences productivity and growth, but also the corresponding progress in physical capital. Our approach considers this link explicitly. Additional varieties emerge with

$$
\dot{N}=\frac{1}{a} L_{g} \cdot N^{\eta}
$$

is the per-unit input coefficient and $L_{g}$ the labour input in capital accumulation and $N$ represents the positive spillover from past capital accumulation. With proportional spillovers $(\eta=1)$ we can write

$$
\frac{\dot{N}}{N} \equiv g=\frac{1}{a} L_{g}
$$

This is the first standard result which is important for the model predictions: the capital accumulation rate is proportional to input quantity in the capital sector $\left(L_{g}\right)$. This quantity depends on total input quantities and the production conditions in the intermediate goods sector (more generally: in the other sectors of the economy). Intermediate goods are produced with energy and labour as inputs (we omit other inputs $V$ in this section for simplicity). To see the basic growth effects of energy in the present approach most clearly, we consider two extreme cases for the substitution between the two inputs. In the first case, input substitution in intermediate goods production is not possible, and second in the second case inputs in intermediate goods production are perfect substitutes. Below, we will extend the analysis to the intermediate cases.

Poor input substitution: If labour $L$ and energy $E$ are pure complements in intermediate goods production, aggregate output of (symmetric) intermediate good firms reads

$$
X=\min \left[b \cdot L_{X}, c \cdot E\right]
$$


where $b, c>0$ are constants. We assume full employment of both inputs and get $X=b \cdot L_{X}=c \cdot E$. The labour market is in equilibrium when:

$$
L_{X}+L_{g}=L
$$

With this we can already derive the impact of energy on the capital accumulation rate. From (4) we have $L_{g}=a g$ and from (5) we get $L_{X}=(c / b) \cdot E$ so that together with (6) we obtain

$$
g=\frac{L}{a}-\frac{c}{a b} \cdot E
$$

This is the next result: In the case of no input substitution in intermediates production, energy $E$ has an unambiguously negative impact on the capital accumulation rate and thus on growth. Note that a high (but constant) $E$ only brings about a high level of $X$ but not a higher growth rate of $X$, so that there is no counteracting force. That an extreme assumption produces an extreme outcome is not surprising. But the implication of the result is remarkable: unlike the results of onesector models, this two-sector model predicts that a decreasing energy input is not necessarily detrimental even when assuming a low input substitution. The mechanism arises because abundant energy causes a large labour input in intermediates production, which leaves little labour for capital accumulation so that the capital accumulation rate becomes low. ${ }^{2}$

Perfect input substitution: If labour $L$ and energy $E$ are perfect substitutes in intermediate goods production, aggregate output of (symmetric) intermediate good firms reads with a unit input coefficient

$$
X=L_{X}+E .
$$

To determine the impact of energy in growth, we need to determine prices, profits, and optimum consumption streams. With free entry into the capital sector, the price of a new capital variety is

$$
p_{N}=a w / n
$$

2 The result corresponds to the outcome in a richer model with three sectors in BRETSCHGER (1998). 
with $w$ being the wage rate. The optimum price of an intermediate good is given by a mark-up over marginal cost, according to:

$$
p_{X}=c_{X} / \beta
$$

where $p_{E}$ is the energy price and $c_{X}=w=p_{E}$. Households can invest in new capital varieties or in bonds which yield a return $r$. The no arbitrage condition reads, in terms of per-period profits $\pi$ and capital gains $\dot{p}_{n}$,

$$
\pi+\dot{p}_{N}=r \cdot p_{N}
$$

The per-period profit flow to the holder of a capital variety $\pi$ is

$$
\pi=(1-\beta) p_{X} X / n
$$

Dividing (11) by $p_{N}$ and using (12) and (9) yields

$$
\frac{(1-\beta) p_{X} X}{a w}+\hat{p}_{N}=r .
$$

From (4), (6) and (8) we have

$$
X=L+E-a g
$$

Moreover, from (9) we get

$$
\hat{p}_{N}=\hat{w}-g=\hat{p}_{X}-g
$$

and $w / p_{X}=\beta$ so that (13) becomes

$$
\frac{(1-\beta)}{\beta}\left(\frac{L+E}{a}-g\right)+\hat{p}_{X}=g+r,
$$

and with the Keynes-Ramsey rule ${ }^{3}$

3 Assuming a logarithmic utility function we get from intertemporal household optimisation $\hat{C}+\hat{p}_{C}=r-\rho$, which is the Keynes-Ramsey rule. Note that $p_{X} X=p_{Y} Y$. Goods markets are in equilibrium when $Y=C$ where $C$ is household consumption $\left(p_{C}=p_{Y}\right)$. 


$$
\frac{(1-\beta)}{\beta}\left(\frac{L+E}{a}-g\right)-\hat{X}=g+\rho .
$$

From the labour market we know that

$$
-\hat{X}=\frac{\dot{g}}{L+E-a g} .
$$

There are no transitional dynamics, the capital accumulation rate jumps directly to the value where $\dot{g}=0$, so that $\dot{X}=0$ and

$$
\frac{(1-\beta)}{\beta}\left(\frac{L+E}{a}-g\right)=g+\rho,
$$

and, finally,

$$
g=(1-\beta) \frac{L+E}{a}-\beta \rho .
$$

Thus, when we have perfect input substitution in intermediates production, energy $E$ is unambiguously good for capital accumulation and growth. The reason is that to have more energy means to have a larger input base for all the sectors, which benefits also the resource sector, where more inputs trigger a higher capital accumulation rate. Furthermore, capital and consumption growth depend positively on the gains from diversification $(-\beta)$ and the productivity in capital accumulation $(1 / a)$ while being negatively affected by the discount rate $\rho$.

Intermediate cases for substitution: When we (realistically) assume that the substitution between energy and labour is between perfect and zero, we write the prices of $x$-goods according to

$$
p_{X}=\left(a_{L X}(\cdot) w+a_{E X}(\cdot) p_{E}\right) / \beta,
$$

where the $a$ again denotes unit input factors, which now depend on relative input prices. In order to solve the system, we have to determine both input prices and the capital accumulation rate endogenously. A change in energy input naturally 
has an effect on all three variables. From the reasoning above, we can infer that a low elasticity of input substitution favours reallocation of labour such that a decreasing energy input is likely to increase capital accumulation. On the other hand, when input substitution is very good, decreasing energy input harms all the sectors including capital production, so that capital growth decreases. Interestingly, the critical value for the elasticity of input substitution (where we have a switch of the impact of energy) is equal to unity in many standard models. ${ }^{4}$ The more general intermediate case for input substitution (with an elasticity between zero and unity) will be used for the numerical simulations below. We will assume in addition that the development of new capital varieties also needs energy as an input and that overall consumption depends on energy. Accordingly, we will have different substitution elasticities that affect the results.

Lessons from theory: The main lesson from our expanding-varieties growth approach is that energy exhibits growth effects which may counteract the better known static effects. Lower energy input leads ceteris paribus to a lower output and consumption level. But in the longer run, ceteris paribus is not applicable. Depending on the substitution effects, inputs will be reallocated between the sectors, which may favour capital accumulation. If so, we get a dynamic effect of lower energy input which leads to more (knowledge) capital accumulation and is positive. In accordance with the literature ${ }^{5}$ we assume input substitution elasticities which are relatively low, that is below unity. Accordingly, when looking at lowering energy input over time, the dynamic simulations below reflect the combination of negative static effects and positive dynamic effects. When extending the substitution mechanisms to more inputs and sectors, we see that the theoretical model has to be extended in order to prepare the ground for the numerical simulations.

Adding more sectors: To capture the economy in more detail, it is usual in numerical simulation models to distinguish between many different sectors, like machinery, chemistry, banking, etc. We follow this tradition and use a different output according to (2) for each sector. The specific feature of our simulation model is then that each sector has its own growth mechanism (as described in this section), which depends on the sectoral characteristics. Intersectoral linkages are modelled in the standard way. It is assumed that the country has a capital market which is independent of the world market, so that the domestic interest rate can

4 See e.g. Bretschger (1998).

5 See e.g. Kemfert (1998) or van der Werf (2007). 
be determined by the own economy. This allows the country to have a growth rate which differs from that of foreign economies.

\section{Data and Parametrization}

For the numerical simulations, we use an extended multi-sectoral version of our framework developed in the previous section. The model includes only one region. International goods trade is modeled via the assumption of Armington goods (i.e. goods are differentiated according to their origin, which makes them imperfect substitutes) ${ }^{6}$. We study the effects of a decreasing energy input on sectoral growth rates and aggregate consumption in the Swiss economy. Energy reduction is induced by a suitable policy, which is a carbon tax.

The simulation model is based on the Swiss input-output table (hereafter named IOT) for the year 2005 (Nathani, van Nieuw koop and Wickart, 2008). It gives detailed information on the flow of goods between sectors and to final demand and also on the use of inputs and on trade. The original table holds data for 42 production sectors and differentiates between fifteen types of consumption (twelve for private households, three for public consumption) and three types of physical investments. As for the use of factor inputs, it holds information on the use of labour and capital. It is therefore an almost complete source of data for the type of model we are using.

For the purpose of our model, the original IOT was aggregated to $12 \mathrm{sec}-$ tors (10 regular production sectors, an energy sector and an oil (sub-)sector, see Table 1 for an overview). Also, we do not differentiate between the different types of consumption and physical investment. Most notably, we do not separate public from private consumption, as there is no explicit representation of the government in the model. Therefore, the different types of consumption were aggregated to one single column. The same was done with physical investments.

However, the model distinguishes two types of investments, physical and non-physical investments. Non-physical investments mainly refers to investments in research and development. The original IOT contains no information on these types of investments. Additionally, there is no reliable data available in Switzerland, especially not on a sectoral level. We therefore use the data from sector 73 ("Research \& Development", where the number 73 refers to the respective NOGA classification) to have an approximate measure for these investments.

6 See Armington (1969). 
Table 1: Overview of the Sectors Used in the Model

\begin{tabular}{lc}
\hline Sector & NOGA-Classifications \\
\hline Agriculture (AGR) & $01-05$ \\
Refined Oil Products (OIL) & 23 \\
Chemical Industry (CHM) & 24 \\
Machinery and Equipment (MCH) & $29-35$ \\
Energy (EGY) & 40 \\
Construction (CON) & 45 \\
Transport (TRN) & $60-63$ \\
Banking and Financial Services (BNK) & 65 \\
Insurances (INS) & 66 \\
Health (HEA) & 85 \\
Other Services (OSE) & 10-22, 25-28, 36-37, 41 \\
\hline Other Industries (OIN) & $50-55,64,70-75,80,90-95$ \\
\hline
\end{tabular}

Put differently, we interpret the demand for goods from sector 73 , i.e. the row entries of this sector in the original IOT, as investments in R\&D of the sectors demanding these goods. To represent this interpretation in the IOT, we transferred these entries into a new column called R\&D investments. Additionally, we use the entry for labour in sector 73 as our benchmark value for aggregate labour in research. Aggregate research labour is then redivided to the sectors according to their share in total capital use. This gives us a value for initial sectoral demand for research labour.

Furthermore, the model differentiates two energy sources: fossil and non-fossil energy. The two sources are aggregated to one energy input that is then used in household consumption and as an input in the production of intermediate varieties. The aggregation to one energy composite is modeled using a CES function, where the elasticity of substitution between the two energy sources is assumed to be below unity. Fossil energy is then further subdivided into refined oil, which is produced in the oil sector (OIL), and gas, which is fully imported. Data for gasimports are taken from the Swiss energy statistics (BUndeSAMt Für ENERGIE, 2006). Non-fossil energy can be interpreted as electricity, data are taken directly from the IOT (sector 40). 
Table 2: Parameter Values

\begin{tabular}{|c|c|c|}
\hline Par. & Description & Value \\
\hline$\sigma_{Y, i}$ & $\begin{array}{l}\text { Elasticity of substitution between Q } \\
\text { and inputs from other sectors }\end{array}$ & $\begin{array}{l}0.392 \text { (AGR), } 0.848 \text { (OIL, CHM), } \\
0.518 \text { (MCH), } 0.100 \text { (EGY), } 1.264 \text { (CON), } \\
0.352 \text { (TRN) } 0.568 \text { (OIN), } 0.492 \text { (rest) }\end{array}$ \\
\hline$\sigma_{X, i}$ & $\begin{array}{l}\text { Elasticity of substitution between the three } \\
\text { inputs (energy, labour and other inputs) }\end{array}$ & $\begin{array}{l}0.7 \text { (AGR, OIL, CHM, EGY) } 0.80(\mathrm{MCH}) \\
0.52 \text { (CON) } 0.82 \text { (OIN), } 0.40 \text { (rest) }\end{array}$ \\
\hline$\sigma_{E}$ & $\begin{array}{l}\text { Elasticity of substitution between fossil } \\
\text { and non-fossil energy }\end{array}$ & 0.3 \\
\hline$\sigma_{I}$ & $\begin{array}{l}\text { Elasticity of substitution between physical } \\
\text { investments and non-physical capital }\end{array}$ & 0.3 \\
\hline$\sigma_{N}$ & $\begin{array}{l}\text { Elasticity of substitution between } \\
\text { investments in } R \& D \text { and research labour }\end{array}$ & 0.3 \\
\hline$\sigma_{C}$ & $\begin{array}{l}\text { Elasticity of substitution between energy } \\
\text { and non-energy goods in consumption }\end{array}$ & 0.5 \\
\hline$\sigma_{W}$ & $\begin{array}{l}\text { Inter-temporal elasticity of substitution in } \\
\text { the welfare function }\end{array}$ & 0.6 \\
\hline$\sigma_{A, i}$ & Armington elasticities & $\begin{array}{l}3.2 \text { (AGR), } 4.6(\mathrm{MCH}) 3.8 \text { (EGY, OIN), } \\
2.9 \text { (rest) }\end{array}$ \\
\hline$\sigma_{T}$ & Elasticity of transformation & 1 \\
\hline
\end{tabular}

The choice of parameter values, most notably of the elasticities of substitution, may have a substantial influence on the model results. It is therefore important to choose these values carefully and reasonably. The elasticities of substitution are set in accordance with given empirical estimations and studies ${ }^{7}$. Sectoral differences in substitutability of inputs on the different levels of the production process are taken into account by setting sectorally differentiated values for the corresponding elasticities whenever available and reasonable. An overview of the elasticities used is given in Table 2 .

7 See e.g. VAn Der Werf (2007) and Okagawa and Ban (2008) for estimations of elasticities related to the production process and Hasanov (2007) for estimates for the intertemporal elasticity of substitution in the utility function. 


\section{Policy Analysis}

\subsection{Description of the Scenarios}

The benchmark scenario of the model is calibrated in order to reflect average growth of output and capital in Switzerland. We assume that capital grows at an annual rate of $1 \%$ in all sectors, which matches the observed growth rate of capital goods in Switzerland since 1990. The parameter $\beta$ determines the share of capital $(1-\beta)$ and, at the same time, reflects the gains from specialization, see Equation 2. It therefore also defines the difference between the growth rate of inputs and (projected) output. In the calibration, $(1-\beta)$ is set to 0.25 in all sectors, which leads to a uniform annual sectoral output growth rate of about $1.33 \%$. Output growth is then in line with the rate assumed in relevant policy scenarios for Switzerland, see Prognos (2007). Importantly, the expansion-invarieties effect is also active in the benchmark scenario. This differentiates our model from other studies, where the endogenous growth mechanisms are only active in the policy scenarios, but not in the benchmark. Using the same growth model in the benchmark and the counterfactuals is, according to our view, a major prerequisite for obtaining reliable and comparable results.

Capital depreciates at a rate starting at $4 \%$. The rate rises moderately every year (ending up at $4.43 \%$ in 2035), which reflects the rising needs to replace capital in an increasingly risky environment and allows bridging the gap between capital and investment growth in the benchmark. The interest rate $r$ can be derived ${ }^{8}$ from total investments in the benchmark and capital stocks as given in the inputoutput table, the depreciation rate and the growth rate of capital goods. Given these values, the interest rate $r$ is equal to 0.016 (or 1.6\%). The implicitly used discount rate $\rho$ is $0.9 \%$, which means that we are employing a very low value, which can be interpreted as a high degree of equality in the treatment of the different generations.

The benchmark scenario is a business-as-usual scenario that abstracts from any political intervention and from any form of taxation (i.e. actual mineral oil taxes are ignored). Most notably, it also neglects climate change and its possible negative effects on the economy and on consumer welfare. While this is a common assumption in energy policy analysis, it is certainly not a fully realistic benchmark case. A more realistic benchmark scenario would aim at incorporating the negative effects of undamped climate change. The Stern Report (STERN, 2007) includes projections of losses in GDP per capita in the absence of climate

8 See Paltsev (2004) for a general discussion of the calibration of dynamic CGE models. 
policy. Due to the long time horizon of these projections, there is considerable uncertainty about the effects on per capita GDP, and the range of possible longterm impacts is large. Moreover, the main negative impact is expected to occur after 2100. Thus for our predictions up to 2035, we stick to the "common" modeling of the benchmark case, which ignores the costs of policy inaction. It has to be kept in mind that the benchmark case applied here may be too optimistic because "business-as-usual" does not apply to nature, especially not in the case of rising greenhouse gas emissions.

As a policy simulation, we implement a scenario that aims at enabling the Swiss economy to reach the ambitious target of a 2000-Watt-society (Jochem et al., 2004 ) in the long run. The vision of a 2000-Watt-society postulates a decrease in constant per capita energy use from the current figure of more than 5000 Watt to 2000 Watt. Scenario IV in the Energy Perspectives (Prognos, 2007) describes an intermediate target on the way to this long-term goal. It claims that energy use has to be reduced by 35\% until 2035 (compared to the year 2000) in order to have a sufficiently high chance of reaching the ultimate goal of a 2000-Wattsociety by the end of the century. Given that the model at hand only considers one region, we implicitly assume that the policy is unilateral.

As a policy instrument, we use a tax levied on the use of fossil energy. Hence, implicitly, we are not only concerned about the reduction in total energy use itself, but also about the composition of the future energy mix. The tax is assumed to be rising over time and set so that the requested target is exactly met. The tax is directly tied to the carbon intensity of the two fossil energy sources. With a uniform tax rate for both sources, this means that oil is effectively taxed at a higher rate than gas. In order to reach the target of a 35\% reduction in 2035, gas has to be taxed at a rate that roughly doubles its price compared to the base year. The price of refined oil has to increase by a factor of about 2.5 by the end of the model horizon.

We differentiate between two sub-scenarios. First, we assume that the tax revenues are redistributed back to the representative household in lump-sum fashion. As an alternative, we present a second scenario where the revenues are used as a subsidy to sectoral capital build-up. The aim of this subsidy is to support the sectoral growth mechanism and therefore to directly counteract the possible drag on sectoral development due to the taxation of fossil energy. The energy sector and the oil sector are excluded from the subsidy in order to avoid any aggravation of the targeted reduction in energy use. 


\subsection{Lump-Sum Redistribution of Tax Revenues}

We first present the results for the base scenario where we assume that the tax is redistributed to the representative household. The graphs show normalized values, with the values in the base period being equal to unity. The time horizon is 25 years, starting in the year 2010 and ending in 2035 where the requested reduction target is achieved. In 2035, this tax profile implies a premium of $9.4 \mathrm{Rp} . /$ $\mathrm{kWh}$ on gas and of $1.2 \mathrm{Fr} . / \mathrm{l}$ on oil'.

Figure 1: Consumption Compared with Benchmark Path (Base Scenario)

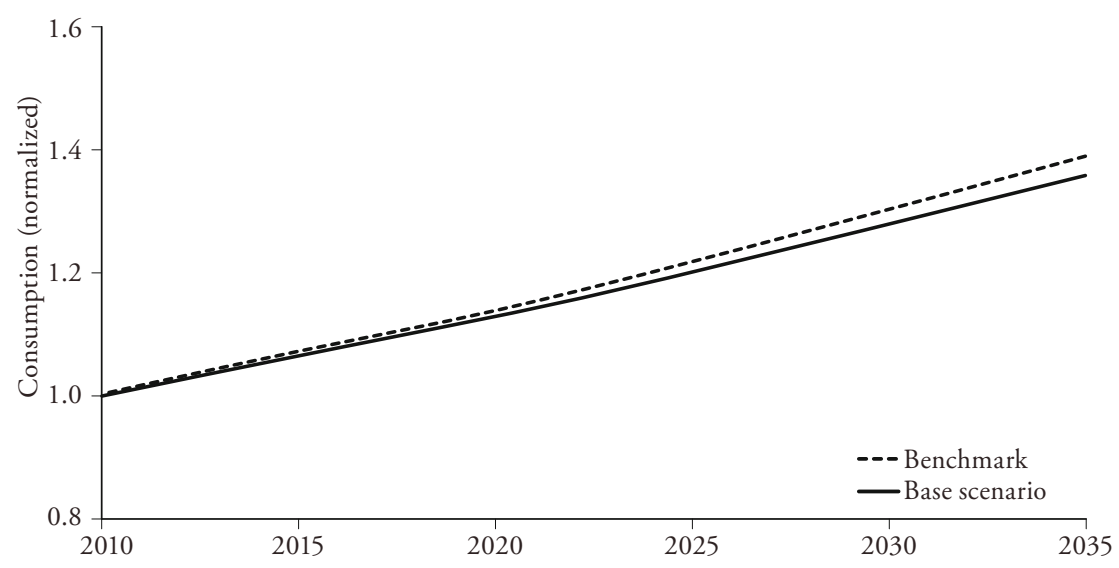

On the aggregate level (see Figure 1), the policy has a relatively moderate (yet not negligible) impact. Compared to the benchmark path, consumption grows at a slightly lower rate. The annual growth rate drops from $1.33 \%$ per year to $1.26 \%$ per year. This leads to a consumption level in 2035 that is approximately $2 \%$ lower than in the benchmark case. The decrease in total welfare, measured by total discounted consumption, is $1.2 \%$. Considering two basic assumptions of the model, this result seems even more encouraging. First, we use a relatively low discount rate of $0.9 \%$ per year. Discounting at a higher rate (e.g. at a rate of

9 These numbers are similar magnitude as in other studies that analyze comparable targets for the Swiss economy, see e.g. Ecoplan (2007a), Ecoplan (2009) or Sceia, Thalmann and VIELLE (2009). 
5\% per year as in Ecoplan 2007a; they find welfare losses below 1\% even for the most ambitious targets) would put lower weight on consumption in the future and thus reduce the loss in welfare considerably ${ }^{10}$. Second, we abstract from secondary benefits of environmental regulation. By explicitly taxing fossil energy, the policy also significantly reduces carbon and local emissions. This may affect consumer welfare positively through better air quality or reduced health costs. Considering these second-order effects would increase utility at every point in time under regulation and therefore reduce the loss in welfare.

At the sectoral level (cf. Figure 2), there are two main points worth noting. First, all regular sectors (i.e. all non energy sectors) continue to grow at robust positive rates. In this sense, the requested decrease in energy use does not pose an existential threat to any of the sectors. Second, the policy does lead to a change in the structure of the economy. As a result of the intervention, sectors deviate from the benchmark paths and grow at different rates. While some sectors are negatively affected in the form of reduced (but still positive) growth rates, others perform even better under the tax regime.

There are two sectors that benefit substantially from the introduction of the tax. Compared to the uniform growth rate of $1.33 \%$ per year in the benchmark, the machinery industry $(M C H)$ and the chemical industry $(C H M)$ increase their average annual growth rates to $1.9 \%$ and $1.54 \%$ respectively. A second group of sectors, the service sectors insurances (INS), banking and financial services $(B N K)$, health $(H E A)$ and other services (OSE) react very moderately to the policy. Their growth rates do not diverge significantly from the business-as-usual path, the exception being INS with an annual growth rate of $1.48 \%$. Finally, several industries grow at lower rates than in the benchmark. Rates range from $1.25 \%$ per year for the construction sector $(C O N)$ and $0.59 \%$ per year for other industries $(O I N)$. Annual growth rates for all sectors and scenarios are reported in Table 3.

A straightforward possible explanation for the observed effects is the energy intensity of the sectors. The more energy a sector uses in its production process, the more it is exposed to the tax and hence the more it is affected by the policy. If we look at the characteristics of the sectors, this does indeed play an important role. Most notably the industries growing at lower rates than in the benchmark are those with the highest shares of energy in production. The service sectors use relatively little energy and therefore react only moderately to a decreasing energy

10 On the other hand, higher discounting would most probably have a negative impact on the investment incentives in our setting, which would increase the welfare loss. The direct effect on consumption is presumably stronger. Checking the sensitivities in this case is difficult in our set-up, because the discount rate essentially depends on the data given in the IOT. 
Figure 2: Growth Paths of Sectoral Output
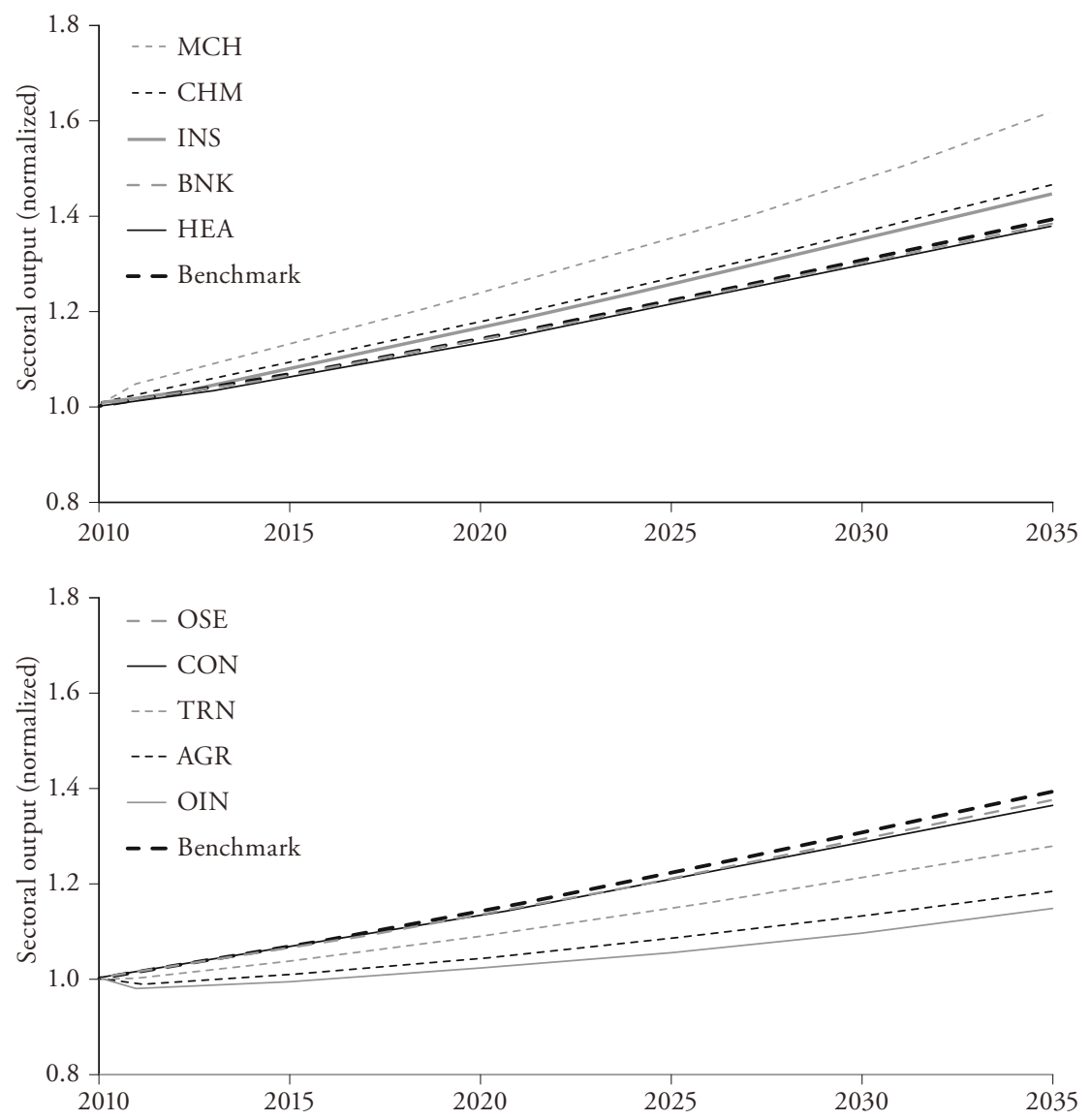

input. $\mathrm{MCH}$ and $\mathrm{CHM}$ are also comparably energy-extensive, but in addition, they are both highly research-intensive, meaning that research and development plays an important role in their production process. This facilitates the substitution of capital for energy and enables them to benefit from the policy.

The underlying model incorporates an expanding variety mechanism that directly links the invention of new capital goods (and thus the accumulation of sectoral capital) to the growth rates of the sectors. Compared to the uniform growth rate in the benchmark, we should therefore see an acceleration of capital accumulation in the sectors that grow at higher rates and reduced growth 
Table 3: Annual Growth Rates in the Different Scenarios

\begin{tabular}{lccc}
\hline & Business-as-usual & lump-sum redistribution & Capital subsidies \\
\hline $\mathrm{MCH}$ & $1.34 \%$ & $1.92 \%$ & $2.31 \%$ \\
$\mathrm{CHM}$ & $1.34 \%$ & $1.54 \%$ & $1.75 \%$ \\
$\mathrm{INS}$ & $1.34 \%$ & $1.48 \%$ & $1.24 \%$ \\
$\mathrm{BNK}$ & $1.34 \%$ & $1.34 \%$ & $1.32 \%$ \\
$\mathrm{HEA}$ & $1.34 \%$ & $1.31 \%$ & $1.28 \%$ \\
OSE & $1.34 \%$ & $1.29 \%$ & $1.32 \%$ \\
$\mathrm{CON}$ & $1.34 \%$ & $1.25 \%$ & $1.56 \%$ \\
TRN & $1.34 \%$ & $1.02 \%$ & $1.07 \%$ \\
AGR & $1.34 \%$ & $0.71 \%$ & $0.67 \%$ \\
OIN & $1.34 \%$ & $0.59 \%$ & $0.57 \%$ \\
Cons. & $1.34 \%$ & $1.26 \%$ & $1.23 \%$ \\
\hline
\end{tabular}

of capital in the sectors with lower output growth rates. Figure 3 confirms this intuition. This highlights that sectoral growth is directly influenced by capital accumulation. Sectors that attract relatively more investments and thus experience faster capital growth also have higher growth rates of output.

But how does a decreasing energy input affect sectoral investment incentives? The taxation of fossil energy increases the price of the energy aggregate and therefore affects the production costs of each variety. Higher production costs for a variety imply a higher cost for the corresponding capital input required to produce the variety. The higher the costs of the capital input, the higher the costs for the investor and thus the lower the incentives to invest. In sectors with a relatively high energy intensity, this effect is stronger than in sectors where energy is less important. Compared to the benchmark, the tax levied on fossil energy induces the investors (i.e. the representative household) to reallocate investments. Sectors with a low energy intensity are relatively more attractive and therefore benefit from increased investments and faster capital accumulation.

Given the explanations above, it may seem straightforward to think that investments should be concentrated in the sector(s) where profit opportunities are the highest. This would imply that the sectors where no more investments are undertaken would disappear. However, the individual sectors are closely interrelated. For example, each sector requires output from other sectors in fixed proportions 
Figure 3: Growth Paths of Total Sectoral Capital Stocks
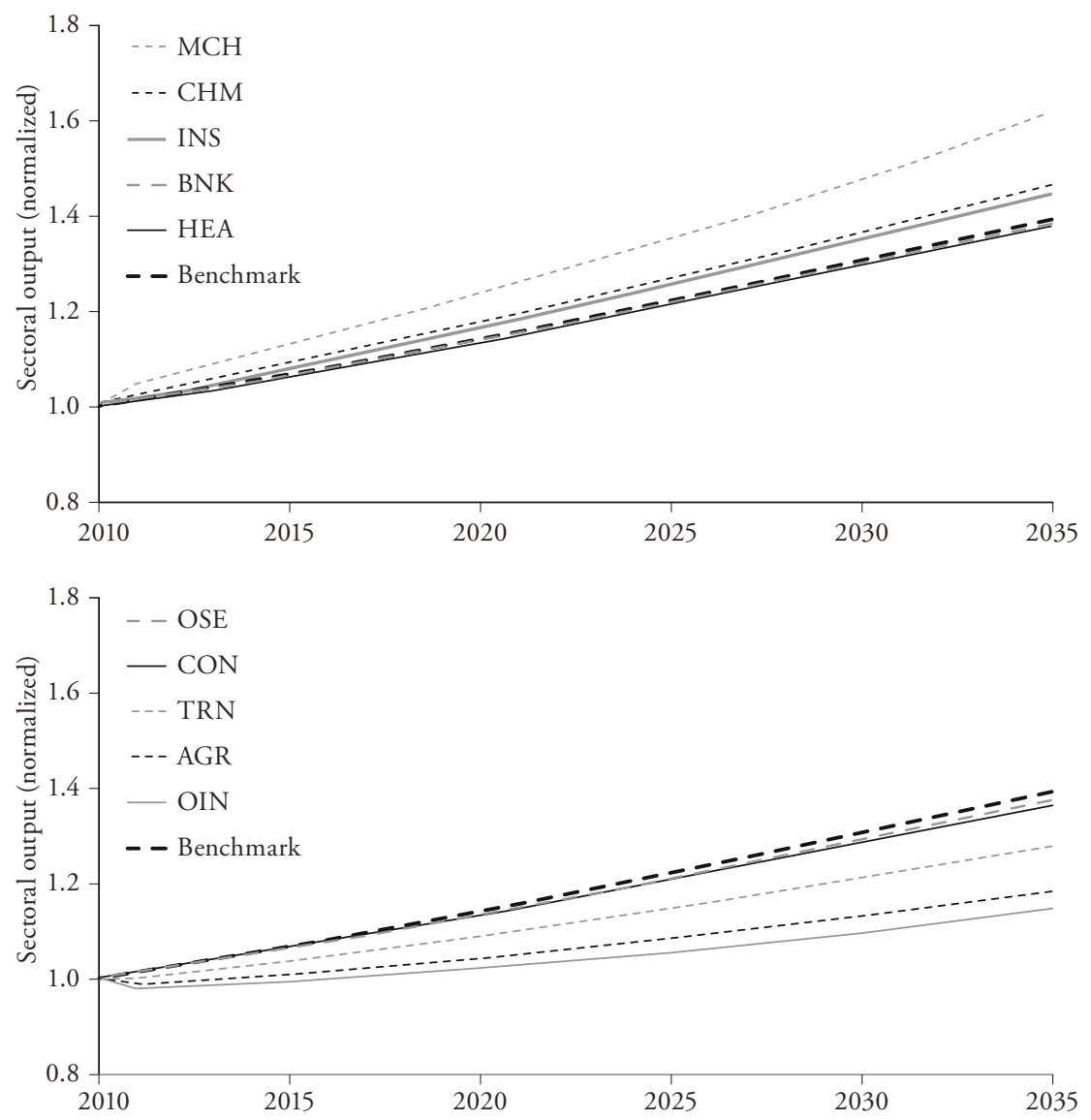

in order to be able to produce. Goods of all sectors therefore have to be supplied in positive quantities at any point in time. This is why capital grows at a rate greater than zero across the whole economy.

\subsection{Capital Subsidies}

In this section, we assume that the revenues of the tax on fossil energy are no longer redistributed as a lump-sum transfer to the representative household. Instead, they are used as a subsidy to sectoral capital build-up. The subsidy 
Figure 4: Growth Paths of Consumption and Aggregate Investments

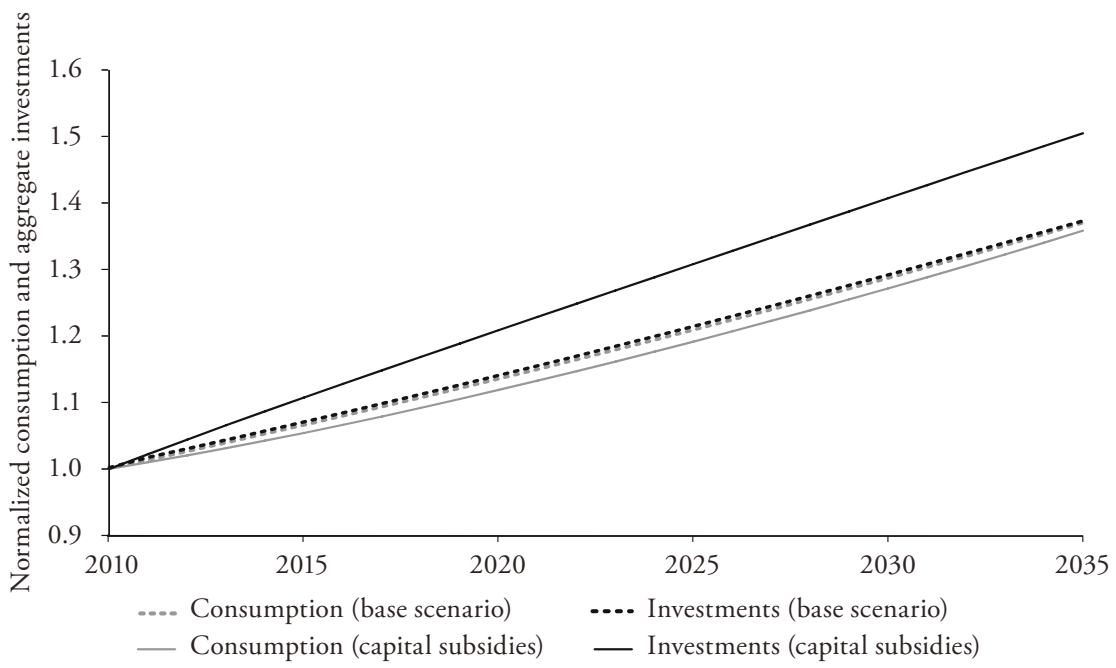

includes both physical and non-physical capital, because both capital types are assumed to have a productive effect. As explained earlier, the idea here is that a direct support of the sectoral growth engines may help to mitigate the negative impacts of taxation. By reducing the costs of new capital varieties, the subsidy aims at increasing the incentives to invest in new capital goods.

Figure 4 compares the growth paths of normalized consumption and aggregate investments (i.e. total investments across all sectors) in the base scenario and the scenario with capital subsidies. The subsidization of capital build-up induces the representative household to devote more of his income to investments and less to consumption. As a result, total investments are significantly higher when capital is subsidized. Consumption on the other hand is higher in the base scenario. Besides the increased incentives to invest, there is an additional reason for the divergence of the two consumption paths. Remember that in the base scenario, the tax revenues are redistributed back to the representative household. This source of income is no longer available when the revenues are used as a capital subsidy. The loss of this source of income adds to the reduction in consumption compared to the base scenario resulting from the increase in investments.

Welfare decreases compared to the base scenario. The total discounted loss in welfare is now $2.0 \%$. Including only consumption, which is reduced as a result 
of the increased devotion of income to investments, it seems straightforward that the welfare loss is higher in this scenario. This may indicate two things. First, assuming that only consumption is relevant for welfare may be a shortcoming. This is, however, a common assumption in this kind of setting. Moreover, possible secondary policy effects are hard to estimate and would therefore not contribute to a better understanding of the resulting welfare effects. Second, it is possible that the benefits (in welfare terms) of subsidizing capital accumulation and thus increasing the incentives for investments can only be reaped in a more distant future. Using the same tax profile, we can indeed show that the welfare loss will eventually become lower than in the scenario with lump-sum redistribution when the time horizon is extended to 70 years or more. The positive impacts on welfare will thus emerge in the long run, and in this sense, the policy modeled here can be viewed as a long-term investment whose benefits (at least on the consumer side) may not immediately become available. On the production side, there are however considerable short-term benefits for certain sectors in the form of higher growth rates.

As indicated above, all sectors except the energy sector and the oil sector benefit from the subsidy. A direct consequence of this is that a lower tax is necessary to reach the reduction target, because the incentives to substitute energy for new capital goods are higher. Energy use can thus be reduced at a lower cost (due to the lower tax rate) than in the base scenario, and the tax burden on the regular sectors can be lowered. This may be another point in favor of a purposeful use of the tax revenues. Due to the increased investments, capital accumulation is accelerated and the productivity (or the efficiency) rises faster than in the base scenario.

Figure 5 compares the normalized sectoral output levels in 2035 (i.e. in the final year of the model horizon) in the two scenarios. Five sectors have (in some cases significantly) higher output levels when capital accumulation is subsidized, while output in the remaining sectors decreases moderately. Sectors that are typically very innovative ( $M C H$ and $C H M$ ) benefit the most from the subsidy. An interesting case is the construction sector $(C O N)$. This sector increases its output significantly compared to the base scenario. As the subsidy also includes investments in physical capital, it implicitly models an important aspect of the Swiss approach to future energy and climate policy. Renovation and better insulation of buildings are expected to contribute significantly to future reductions in energy demand. Parts of the revenues of the tax on fossil fuel use for heating purposes (introduced in 2008) are used for an extensive program that supports building renovation ("Gebäudeprogramm") and therefore directly aims at increasing the energy efficiency of buildings. The construction sector is supposed to benefit 
Figure 5: Normalized Sectoral Output in 2035

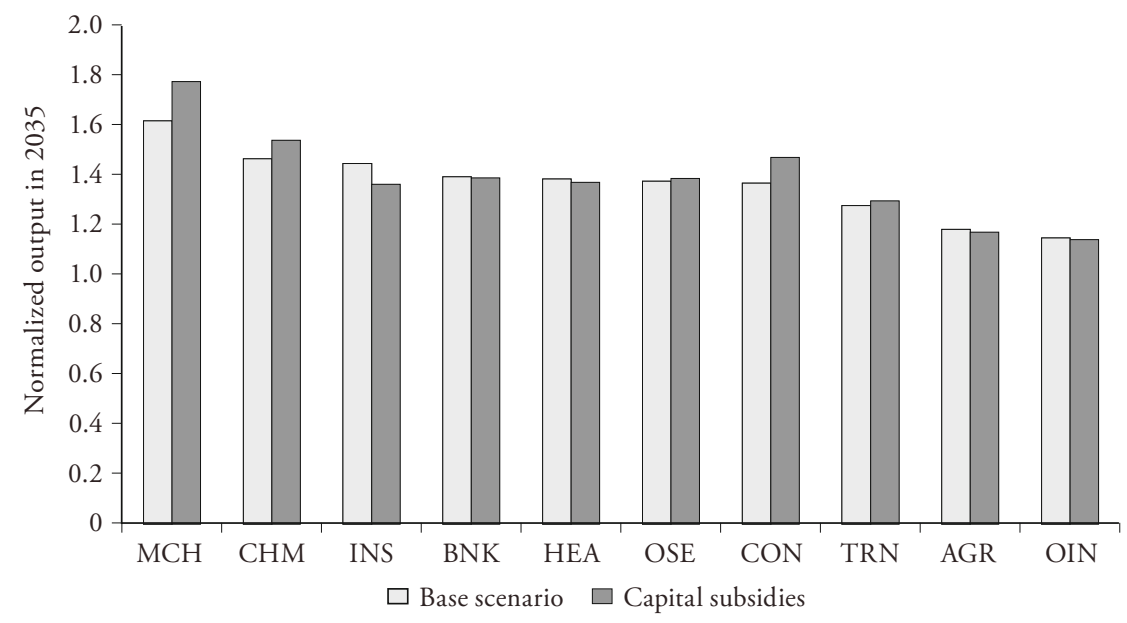

greatly from this program. The policy we model here has a somewhat broader purpose, but by subsidizing investments in physical capital, it captures a key element of Swiss energy policy.

Hence, in contrast to the adverse short-run effects on welfare, the subsidy also has a number of positive effects. It supports capital build-up in innovative sectors and thereby accelerates the productivity gains significantly. And by intensifying the structural effects, it also increases the share of relatively energy-extensive sectors in total production and therefore facilitates the shift towards a less energy-intensive economy.

\section{Sensitivity Analysis}

In this section, we present a brief sensitivity analysis based on the scenario discussed in Section 4.2. In order to test the robustness of the model results, we vary the values of the elasticities of substitution on the different levels of production and in the nested functions of consumption and investments. Additionally, we also consider changes of the Armington elasticities and the elasticity of transformation. The values are all varied individually, hence we abstract from testing for the effects of joint variations. Except for one case, the base values of the 
elasticities of substitution are doubled or halved. The exception is given by the Armington elasticities, where doubling the values would lead to unrealistically high numbers that eventually prevent the model from solving. In this case, we made smaller adjustments ( +1 and -1 respectively).

The results of the sensitivity check are presented in Table 4 . The sensitivities are expressed as differences from the results using the original values as given in Table 2. They should be interpreted as follows. If for example the tax leads to an increase in output of a sector of $2.4 \%$ in the simulation with the standard values, an entry of - 0.001 in Table 4 means that the increase is only $2.3 \%$ if the corresponding elasticity is adjusted. $Y_{\text {top }}$ and $K_{\text {top }}$ refer to output and capital stock of the sector with the highest value in the year 2035. $Y_{b o t}$ and $K_{b o t}$ denote the values of the sector that is most negatively affected. By looking at the top and bottom levels of sectoral output and capital, we can investigate how the intensity of structural change is affected. $C$ (total consumption in the year 2035) and $W$ (welfare) are used to study the impacts at the aggregate level.

Table 4 confirms that the model results are robust with respect to most parameter values. The elasticities in the nested consumption and investment functions $\left(\sigma_{C}, \sigma_{I}\right.$ and $\left.\sigma_{N}\right)$ as well as the elasticity of substitution between fossil and nonfossil energy $\left(\sigma_{E}\right)$ and the intertemporal elasticity of substitution in the utility function $\left(\sigma_{W}\right)$ have a very moderate impact on the results.

The effects of the elasticities in the nested production functions of the sectors are a bit more pronounced. Better substitutability on the top level of the nesting (reflected by higher values for $\sigma_{Y}$ ) amplifies the structural effects. A more flexible production structure leads to an increased shift of investments towards sectors with a lower energy-intensity and thus leads to a wider range of output levels in 2035. The opposite holds when $\sigma_{Y}$ is decreased. Higher values for $\sigma_{X}$, the parameter reflecting the substitutability of factor inputs (labour, energy and other inputs) in the production of intermediate varieties, leads to a stronger impact of a given tax profile. This is directly related to the remarks made in Section 2. Better substitutability for energy implies an increased demand for labour and other inputs and a lower need to invest in new capital varieties. On the other hand, stronger complementarity between the factors leads to an upward shift in capital accumulation and output in all sectors. An explanation for this is that reduced direct substitution potentials for energy increase the need to invest in new capital varieties. As a result, output grows at a higher rate in all sectors.

The trade elasticities have the largest effect. The machinery industry, the sector with the highest output level, is a very trade intensive sector. Increasing either the corresponding Armington elasticity or the elasticity of transformation therefore has a significant positive impact on both output and capital accumulation of this 
sector. Consequently, structural change is again intensified due to the fact that a higher share of total investments is directed towards the trade intensive sectors. The exact opposite holds when the trade elasticities are reduced. A reduced substitutability between domestic and foreign goods mitigates the reallocation of investments and thereby reduces the structural effects.

Table 4: Sensitivities with Respect to Variations of the Elasticities of Substitution

\begin{tabular}{|c|c|c|c|c|c|c|}
\hline & $Y_{\text {top }}$ & $Y_{b o t}$ & $K_{t o p}$ & $K_{b o t}$ & $C$ & $W$ \\
\hline$\sigma_{C}(d o u b)$ & -0.003 & -0.055 & 0.000 & -0.055 & -0.001 & -0.001 \\
\hline$\sigma_{C}($ half $)$ & 0.002 & 0.032 & -0.002 & 0.032 & 0.001 & 0.001 \\
\hline$\sigma_{E}($ doub $)$ & -0.019 & -0.024 & -0.018 & -0.025 & 0.002 & 0.001 \\
\hline$\sigma_{E}($ half $)$ & 0.009 & 0.010 & 0.007 & 0.011 & 0.000 & 0.000 \\
\hline$\sigma_{I}($ doub $)$ & 0.001 & 0.000 & 0.000 & 0.000 & 0.000 & 0.000 \\
\hline$\sigma_{I}($ half $)$ & 0.000 & 0.000 & -0.001 & 0.000 & 0.000 & 0.000 \\
\hline$\sigma_{N}($ doub $)$ & 0.001 & 0.000 & 0.000 & 0.000 & 0.000 & 0.000 \\
\hline$\sigma_{N}($ half $)$ & 0.000 & 0.000 & -0.001 & 0.000 & 0.000 & 0.000 \\
\hline$\sigma_{W}($ doub $)$ & -0.021 & -0.002 & -0.030 & -0.007 & -0.001 & 0.003 \\
\hline$\sigma_{W}($ half $)$ & 0.030 & 0.002 & 0.038 & 0.008 & 0.001 & -0.002 \\
\hline$\sigma_{Y, i}(d o u b)$ & 0.052 & -0.011 & 0.065 & -0.094 & 0.000 & 0.000 \\
\hline$\sigma_{Y, i}($ half $)$ & -0.017 & 0.004 & -0.022 & 0.037 & 0.001 & 0.001 \\
\hline$\sigma_{X, i}($ doub $)$ & -0.064 & -0.101 & -0.050 & -0.103 & -0.005 & -0.002 \\
\hline$\sigma_{X, i}($ half $)$ & 0.035 & 0.060 & 0.025 & 0.060 & 0.004 & 0.002 \\
\hline$\sigma_{A, i}(+1)$ & 0.386 & -0.145 & 0.321 & -0.143 & -0.008 & -0.004 \\
\hline$\sigma_{A, i}(-1)$ & -0.120 & 0.076 & -0.103 & 0.073 & 0.003 & 0.002 \\
\hline$\sigma_{T}(d o u b)$ & 0.107 & -0.018 & 0.085 & -0.016 & 0.000 & 0.000 \\
\hline$\sigma_{T}($ half $)$ & -0.029 & 0.010 & -0.025 & 0.010 & 0.001 & 0.001 \\
\hline
\end{tabular}




\section{Conclusions}

The paper has investigated the energy-growth relationship both theoretically and numerically. In the theoretical part, we demonstrate that a decreasing energy input is not unambiguously bad for growth. Using an expanding-variety framework where growth is driven by enhancements of the capital stock, we find that a reduced availability of energy may even stimulate sectoral development. If energy and the other inputs used in final goods production are complements, a decreasing energy input will redirect resources to capital accumulation and thereby accelerate growth. The opposite holds when energy and the other factor inputs are perfect substitutes. Parameter estimations (which are also used in the simulation part) indicate that the elasticity of substitution most likely lies between zero and unity, with relatively poor substitution being the most relevant case.

We test the consequences of a policy aiming at decreasing energy use in the Swiss economy using a one-region multi-sector CGE model with a sector-specific expanding variety mechanism that drives growth. We find that a policy that lowers energy use by $35 \%$ until 2035 has relatively moderate effects on aggregate growth, with welfare decreasing by $1.2 \%$ compared to the business-as-usual scenario. At the sectoral level, the policy induces a change in the structure of the economy. Industries with a low energy share and/or high innovative activity perform relatively better when the energy input is decreasing over time. These sectors accumulate more capital and thereby grow at higher rates than sectors that rely heavily on energy. Furthermore, the results indicate that the adverse effects of the regulation can be mitigated in most sectors when energy policy is coupled with a subsidization of investments in new capital varieties.

In comparison with models relying partly or only on exogenous growth and technological change, modeling growth as purely endogenous captures a broader range of impacts on the economy. If the economy grows at a predefined fixed rate, the reactions of the different actors to a given policy (a carbon tax in our case) have no impact on the development on the economy. Structural change then only results because the sectors have different fossil-fuel intensities and are unequally exposed to the policy. In our setting, there is an additional channel. Policies also affect the incentives to invest, and these incentives have an impact on sectoral growth. Because a larger spectrum of policy effects are captured, we can expect that the inclusion of endogenous growth amplifies the effects that can be observed in models with a more simplified representation of economic growth. Indeed, when comparing the magnitude of our structural effects to those e.g. in ECOPLAN (2007b), our setting produces significantly larger percentage changes in sectoral output, both on the positive and on the negative side. Finally, 
the effects on sectoral growth rates and on welfare reported in the present paper are a bit smaller than in BRETSCHGER, RAMER and SCHWARK (2011), which can be explained by the shorter time horizon and the lower stringency of the policy under consideration.

The existing model can be extended in various respects. The inclusion of more regions would enable considering a number of aspects that might play a role in such a setting. With respect to innovation, international spill-overs of knowledge are of particular importance, especially for a small open economy like Switzerland. Regionally diverging policies and the resulting impacts on investment incentives are an additional interesting application that could be studied in a multi-region framework. An extension of the model would also include a more detailed representation of the energy sector and the relevant technologies. This would render the modeling of more specific learning effects possible. The resulting efficiency gains may be an important factor in reducing future energy use. These tasks are left for future research.

\section{References}

Armington, Paul S. (1969), "A Theory of Demand for Products Distinguished by Place of Production", Staff Papers - International Monetary Fund 16, pp. 159-178.

Bosetti, Valentina, Carlo Carraro, and Marzio Galeotti (2006), "The Dynamics of Carbon and Energy Intensity in a Model of Endogenous Technical Change", The Energy Journal, Endogenous Technological Change and the Economics of Atmospheric Stabilisation Special Issue, pp. 191-206.

Bretschger, Lucas (1998), "How to Substitute in Order to Sustain: Knowledge Driven Growth under Environmental Restrictions", Environment and Development Economics 3(4), pp. 425-442.

Bretschger, Lucas, Roger Ramer, and Florentine Schwark (2011), "Growth Effects of Carbon Policies: Applying a Fully Dynamic CGE Model with Heterogeneous Capital", Resource and Energy Economics 33 (4), pp.963-980.

Bretschger, Lucas, Roger Ramer, and Florentine Schwark (2010), "Impact of Energy Conservation Policy Measures on Innovation, Investment and Long-Term Development of the Swiss Economy: Results from the Computable Induced Technical Change and Energy (CITE) Model", Final report for EWG project 101844, prepared for the Swiss Federal Office of Energy, Bern, Switzerland. 
Bundesamt für Energie (2006), Schweizerische Gesamtenergiestatistik 2005, Bern.

Buonanno, Paolo, Carlo Carraro, and Marzio Galeotti (2003), "Endogenous Induced Technical Change and the Costs of Kyoto", Resource and Energy Economics 25, pp. 11-34.

Dixit, Avinash K. and Joseph E. Stiglitz (1977), "Monopolistic Competition and Optimum Product Diversity", The American Economic Review 67 (3), pp. 297-308.

Ecoplan (2007a), „Die Energieperspektiven 2035 - Band 3. Volkswirtschaftliche Auswirkungen. Ergebnisse des dynamischen Gleichgewichtsmodells, mit Anhang über die externen Kosten des Energiesektors", Bern.

ECOPLAN (2007b), „Auswirkungen langfristig hoher Ölpreise. Einfluss eines hohen langfristigen Ölpreises auf Wirtschaftswachstum, Strukturwandel sowie Energieangebot und -nachfrage“, Bern.

Ecoplan (2009), „Volkswirtschaftliche Auswirkungen der Schweizer Post-Kyoto Politik. Analyse mit einem Gleichgewichtsmodell für die Schweiz", Bern.

Edenhofer, Ottmar, Nico Bauer, and Elmar Kriegler (2005), "The Impact of Technological Change on Climate Protection and Welfare: Insights from the Model MIND", Ecological Economics 54, pp. 277-292.

Ethier, Wilfried J. (1982), "National and International Returns to Scale in the Modern Theory of International Trade", The American Economic Review 72 (3), pp. 389-405.

Goulder, Lawrence H. and Stephen H. Schneider (1999), "Induced Technological Change and the Attractiveness of CO2 Abatement Policies", Resource and Energy Economics 21, pp. 211-253.

Grossman, Gene M. and Elhanan Helpman (1991), Innovation and Growth, The MIT Press, Cambridge, USA.

Hasanov, Fuad (2007), "Housing, Household Portfolio, and Intertemporal Elasticity of Substitution: Evidence from the Consumer Expenditure Survey", EconWPA, Macroeconomics 0510011.

Heggedal, Tom-Reiel and Karl Jacobsen (2011), "Timing of Innovation Policies when Carbon Emissions are Restricted: An Applied General Equilibrium Analysis", Resource and Energy Economics, 33 (4), pp. 913-937.

Jochem, Eberhard et al. (2004), "Steps Towards a Sustainable Development. a White Book for R\&D of Energy-Efficient Technologies”, CEPE/ETH Zurich and Novatlantis, Zurich.

Kemfert, Claudia (1998), "Estimated Substitution Elasticities of a Nested CES Production Function Approach for Germany", Energy Economics 20, pp. 249-264. 
Nathani, Carsten, Marcel Wickart, and Renger van Nieuw koop (2008), „Revision der IOT 2001 und Schätzung einer IOT 2005 für die Schweiz“, Centre for Energy Policy and Economics (CEPE), ETH Zuerich; Ecoplan, Forschung und Beratung in Wirtschaft und Politik; Rütter + Partner, Zürich / Bern / Rüschlikon.

Nordhaus, William D. (2002), "Modeling Induced Innovation in Climate Change Policy", in Arnulf Grübler, Nebjosa Nakicenovic and William D. Nordhaus (2002), Modeling Induced Innovation in Climate Change Policy, Resources for the Future Press.

Okagawa, Azusa and Kanemi Ban (2008), "Estimation of Substitution Elasticities for CGE models", Graduate School of Economics and Osaka School of International Public Policy, Discussion Paper 08-16.

Otto, Vincent M., Andreas Löschel, and Rob Delink (2007), "Energy Biased Technical Change: A CGE Analysis", Resource and Energy Economics 29 (2), pp. 137-158.

Paltsev, Sergey (2004), "Moving from Static to Dynamic General Equilibrium Economic Models (Notes for a Beginner in MPSGE)", Technical Note No. 4, MIT Joint Program on the Science and Policy of Global Change.

Pittel, Karen and Lucas Bretschger (2010), "The Implications of Heterogeneous Resource Intensities on Technical Change and Growth", Canadian Journal of Economics 43 (4), pp. 1173-1197.

Prognos (2007), "Die Energieperspektiven 2035 - Band 2. Szenarien I bis IV", Bern.

Romer, Paul M. (1990), "Endogenous Technological Change", The Journal of Political Economy 98 (5), pp. 71-102.

Sceia, André, Philippe Thalmann, and Marc Vielle (2009), "Assessment of the Economic Impacts of the Revision of the Swiss $\mathrm{CO}_{2}$ Law with a Hybrid Model", REME-REPORT-2009-002.

Smulders, SjaK and Michiel de Nooij (2003), "The Impact of Energy Conservation on Technology and Economic Growth", Resource and Energy Economics 25 (1), pp. 59-79.

Spence, Michael (1976), "Product Selection, Fixed Costs, and Monopolistic Competition", Review of Economic Studies 43, pp. 217-235.

Stern, Nicolas (2007), "The Stern Review Report: The Economics of Climate Change", Cambridge University Press, Cambridge.

Sue Wing, Ian (2003), "Induced Technical Change and the Cost of Climate Policy", MIT Joint Program on the Science and Policy of Global Change, Report No. 102. 
van der Werf, Edwin (2007), "Production Functions for Climate Policy Modeling: An Empirical Analysis", Energy Economics 30, pp. 2964-2979.

Xepapadeas, Anastasios, and Aart de Zeeuw (1999), "Environmental Policy and Competitiveness: The Porter Hypothesis and the Composition of Capital", Journal of Environmental Economics and Management 37, pp. 165-182.

\section{Appendix: Nested Production Functions}

Figure 6: Nested Production Function of Regular Sectors

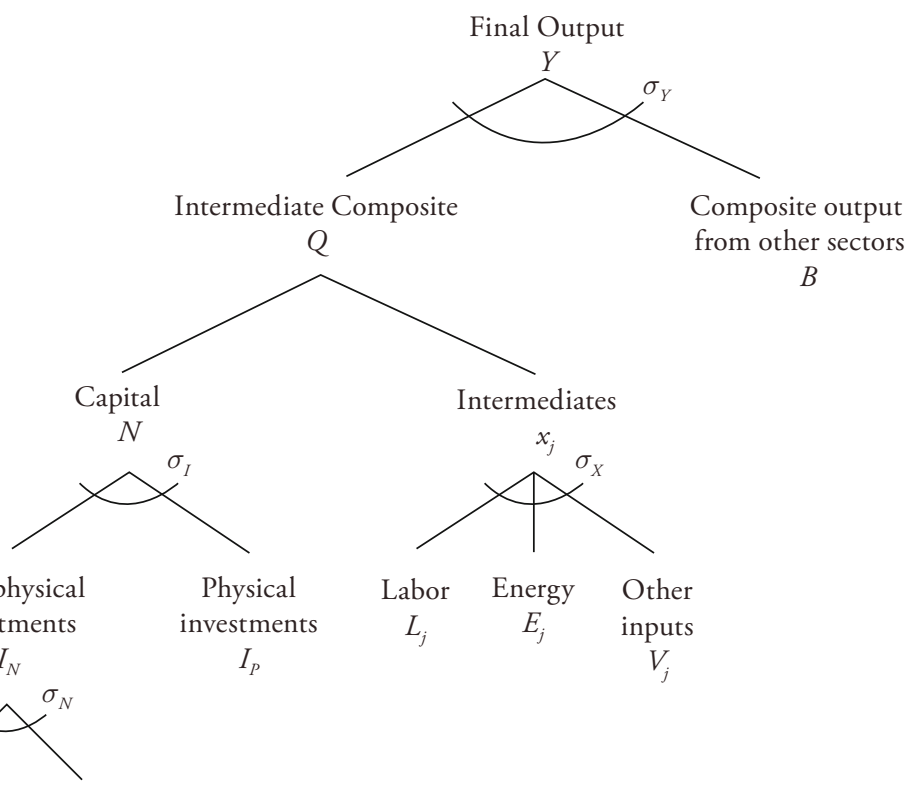

Labor in Investments

research in $\mathrm{R} \& \mathrm{D}$

$L_{g} \quad I_{R}$ 
Figure 7: Nested Production Function of the Energy Sector

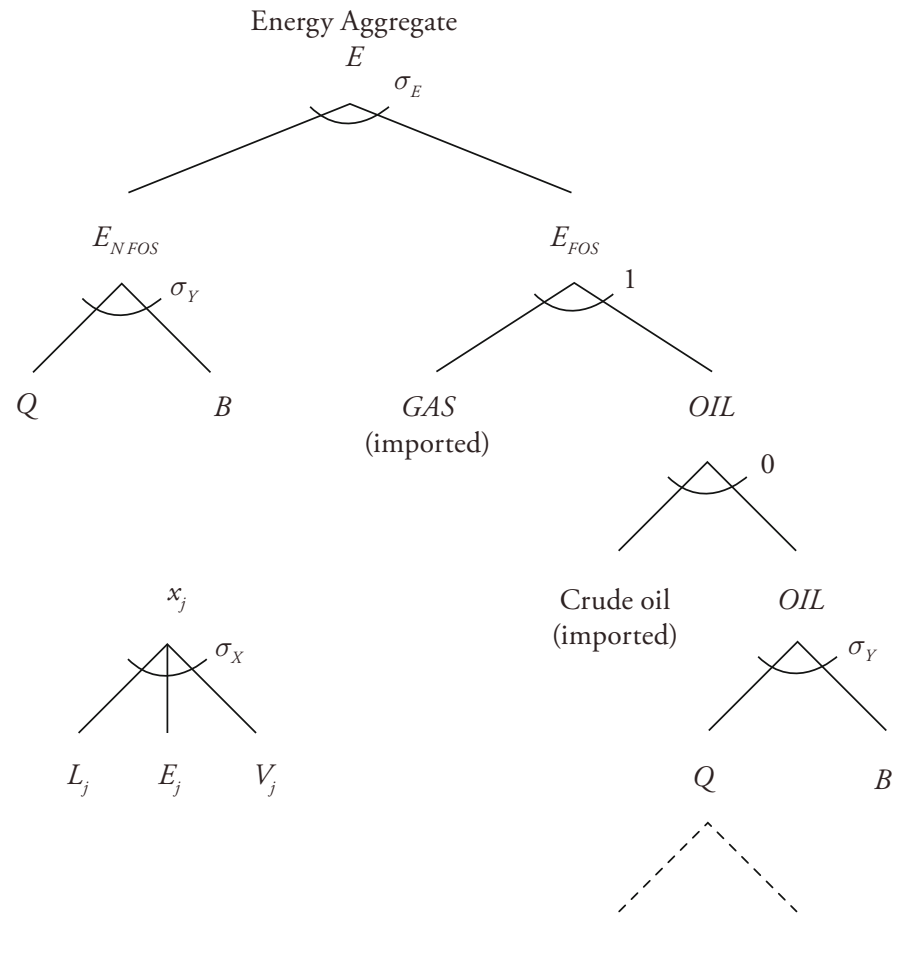

\section{SUMMARY}

The paper applies a theoretical model with increasing capital varieties to study the impact of energy on growth. It translates a multisectoral framework version to a computable general equilibrium (CGE) model of the Swiss economy. We study the impacts of a policy aiming at enabling the economy to reach the longterm target of a 2000-Watt-society, implying a substantial reduction of the energy input in the future. We find that (i) the aggregate effects of an ambitious energy efficiency policy turn out to be moderate, (ii) all sectors in the economy continue to grow at robust positive rates (although growth rates decrease in some sectors compared to business-as-usual), and (iii) some industries experience substantially higher growth under regulation. We focus on the different sectoral growth effects to simulate future structural change. 